\title{
ISTRAŽIVAČKE VEŠTINE I STRATEGIJE STUDENATA ENGLESKOG JEZIKA I KNJIŽEVNOSTI: KVALITATIVNA
} ANALIZA $^{1}$

Jedan od prvih koraka u pisanju akademskog teksta, sem formulacije istraživačkog pitanja, svakako jeste pretraživanje literature i nalaženje relevantnih izvora informacija koje će pisac naučnog teksta koristiti kao osnov novog istraživanja. Ovo je jedna od najneophodnijih veština u oblasti akademskog pisanja, naročito u dvadeset prvom veku, kada je na internetu dostupno toliko informacija da dolazi do prezasićenja, ali i svojevrsne nemogućnosti da se sa sigurnošću odabere dobar, relevantan i pouzdan izvor. Ovaj rad se upravo bavi problemom istraživačkih veština studenata, a zasnovan je na analizi sadržaja 73 izveštaja studenata četvrte godine Engleskog jezika i književnosti na Filozofskom fakultetu u Novom Sadu. Oslanjajući se na kvalitativni pristup studentskoj naraciji, rad će pokušati da utvrdi sa kojim se problemima studenti sreću prilikom procesa istraživanja za projekat na predmetu Engleski jezik 9, koje strategije koriste prilikom istraživanja, kao i koja su moguća rešenja za datu situaciju.

Ključne reči: akademsko pisanje, istraživačke veštine, istraživačke strategije, preporuke, kvalitativna analiza, naracija.

\section{UVOD}

Bez obzira na oblast visokoškolskog obrazovanja i naučnog delovanja, akademsko pisanje igra izuzetno značajnu ulogu kao sredstvo beleženja novih saznanja i prenosa postojećih informacija. Jedan od prvih koraka u akademskom pisanju, sem formulacije istraživačkog pitanja, svakako jeste pretraživanje literature i nalaženje relevantnih izvora informacija koje će pisac naučnog teksta koristiti 1 Ovaj rad je rezultat istraživanja na projektu 178002 „Jezici i kulture u vremenu i prostoru“ koji finansira Ministarstvo prosvete i nauke Republike Srbije. 
kao osnov novog istraživanja. Iako tako ne deluje na prvi pogled, ovo je jedna od najneophodnijih veština u oblasti akademskog pisanja, naročito u dvadeset prvom veku, kada je na internetu dostupno toliko informacija da dolazi do prezasićenja, ali i svojevrsne nemogućnosti da se sa sigurnošću odabere dobar, relevantan i pouzdan izvor.

Pošto se akademskim pisanjem ne bave samo naučni radnici, nego njegove osnove savladavaju i početnici na polju nauke, tj. studenti, potreba za razvojem ove veštine sve je veća, jer studenti nemaju iskustvo na koje mogu da se oslone, niti imaju dovoljno znanja iz date oblasti da bi mogli da razviju kritički stav prema onome što pročitaju. Stoga se sa pravom može reći da je veština akademskog istraživanja jedna od najbitnijih koje bi studenti trebalo da savladaju da bi sa uspehom mogli da ispunjavaju akademske zadatke tokom svojih studija (npr. istraživački projekat, seminarski rad, prezentacija, itd). Ovo, dakle, podrazumeva da bi oni trebalo da se osposobe da pronađu relevatne izvore informacija i da ih pravilno iskoriste.

Ovaj rad se upravo bavi problemom istraživačkih veština studenata, a zasnovan je na analizi sadržaja 73 izveštaja studenata četvrte godine Engleskog jezika i književnosti na Filozofskom fakultetu u Novom Sadu. Oslanjajući se na kvalitativni pristup studentskoj naraciji, rad će pokušati da utvrdi sa kojim se problemima studenti sreću prilikom procesa istraživanja za projekat na predmetu Engleski jezik 9, kao i koja su moguća rešenja za datu situaciju.

\section{ISTRAŽIVAČKE VEŠTINE}

Razrađujući materijal za razvoj veštine pretraživanja i istraživanja kod studenata, Manning et al. (2007: 306-322) navode da bi studenti trebalo budu svesni toga šta sve može da bude izvor informacija, da budu sposobni da prepoznaju ili uoče dobre i loše strane različitih izvora i različitih vrsta izvora, kao i da beleže bibliografske podatke o knjigama i vebsajtovima koje koriste tokom pripreme i istraživanja. S obzirom na nemerljivu količinu podataka i različitost izvora koji se mogu naći na internetu, studenti bi morali da budu sposobni da prilikom pretrage procene kredibilitet materijala koji će pronaći i da donesu sud o statusu i relevantnosti velikog broja tekstova o jednoj temi (Alexander et al. 2008: 124). Problem je tim veći što u ovakvoj vrsti pretrage ne postoji filter kredibilnosti kao što je biblioteka 
ili izdavač, koji bi mogli na neki način da razgraniče vrednije izvore od onih manje vrednih, a većina studenata, $\mathrm{s}$ druge strane, ne znajući kako da proceni izvor podataka, najčešće ide linijom manjeg otpora i koristi uglavnom prvih nekoliko linkova koji im se pokažu kao rezultati pretrage na internetu.

Savetodavnu ulogu bibliotekara danas u izvesnoj meri zamenjuju akademske baze podataka, koje funkcionišu kao filteri kredibilnosti izvora, pošto materijali do kojih se preko njih može doći moraju da ispunjavaju određene akademske kriterijume (pouzdanost, relevantnost, autoritativnost izvora, itd.). S druge strane, pitanje je koliko studenti koriste ovaj izvor informacija i materijala, koliko su upoznati sa mogućnostima koje akademske baze nude i koliko su spremni da potraže pomoć ako ne umeju da ih koriste. U istraživanju sprovedenom sa 135 studenata Engleskog jezika i književnosti na sve četiri godine studija, Radić-Bojanić i Topalov (2012) ustanovile su da studenti u osnovi nisu dovoljno dobro upoznati sa akademskim bazama podataka, kao i da „sa godinom studija raste i poznavanje različitih bibliotečkih sistema koji se studentima nalaze na raspolaganju“ (Radić-Bojanić i Topalov 2012: 37). Sem toga, isto istraživanje je utvrdilo da su studenti ubeđeni da im ne treba pomoć u korišćenju onlajn-izvora, iako detaljnija analiza otkriva „da su studenti nižih godina samouvereniji, ali ne zbog znanja, nego zbog toga što nisu svesni šta postoji na akademskom nivou i šta je razlika između akademskih i neakademskih izvora materijala“ (Radić-Bojanić i Topalov 2012: 38). Nasuprot tome, studenti viših godina imaju izraženiju svest o postojanju različitih izvora, kao i o različitim stepenima njihove kredibilnosti, ali glavni problem i dalje jeste to što ne znaju kako da te izvore koriste.

Drugi deo pomenutog istraživanja, čiji su rezultati predstavljeni u Topalov i Radić-Bojanić (2012), istraživačke veštine studenata stavlja u širi kontekst njihovih navika vezanih za upotrebu interneta uopšte. Tako statistička analiza rezultata otkriva da je četvrta godina spremnija da koristi onlajn-izvore od studenata sa ostalih godina studija, kao i da isti studenti, prilikom pretraživanja interneta, pogledaju dve ili više stranica rezultata dobijenih pretragom. Nasuprot tome, mlađi studenti najčešće pogledaju samo prva tri rezultata na prvoj stranici, a ponekad pregledaju i sve rezultate na prvoj stranici. Sve ovo navodi na zaključak da studenti završne godine fakulteta po veštinama istraživanja i osvešćenosti po pitanju potencijalnih istraživačkih problema odstupaju od svojih mlađih kolega. Iz tog razloga, istraživanje predstavljeno u ovom 
radu usredsređuje se samo na ove studente i posmatra proces istraživanja koji su sproveli za projekat na predmetu Engleski jezik 9 u nadi da će „pogled iznutra“ otkriti njihova mišljenja, stavove i probleme sa kojima se suočavaju, što u dijagnostičkom smislu može da se iskoristi kao osnova za sistemsko osmišljavanje rešenja za dati problem.

\section{METODOLOGIJA ISTRAŽIVANJA}

Kvalitativno istraživanje se usredsređuje na ponašanje ljudi u prirodnom okruženju i posmatra kako se oni ponašaju u njemu (Tullis Owen 2008). Ovakav pristup se zasniva na shvatanju da je kontekst od suštinske važnosti u razumevanju ljudskog ponašanja (što je od naročitog značaja u domenu socioloških i antropoloških istraživanja), kao i da učenje o ljudskom iskustvu van prirodnog konteksta nije moguće, jer prava slika o složenosti ljudske interakcije može tek da se dobije u svakodnevnom okruženju, a ne u kontrolisanim laboratorijskim uslovima (Eisner 1991: 32-33). Analiza podataka iz kvalitativnog istraživanja zasniva se na utemeljenoj teoriji, što istraživaču omogućava da svoje rezultate stavi u širi kontekst. Sami rezultati se opisuju i predstavljaju u onom obliku koji omogućava izuzetno detaljan opis ljudskog ponašanja, pri čemu se tumačenja rezultata predstavljaju kao iskustva učesnika u istraživanju (Eisner 1991: 35).

U okviru kvalitativnog istraživanja sakupljanje podataka gotovo uvek uključuje neku vrstu interakcije licem u lice između istraživača i učesnika istraživanja. Samo sakupljanje podataka može da se odvija posmatranjem (istraživač beleži ono šta vidi), intervjuisanjem (istraživač beleži ono što mu učesnici istraživanja kažu), traženjem odgovora (npr. upitnik), naracijom (učesnici u pisanom obliku prenose svoja iskustva), itd. Eisner (1991: 37) dovodi u vezu kvalitativno istraživanje i naraciju u domenu obrazovanja. Naracija pruža uvid u to kako učenici doživljavaju svet oko sebe, jer oni na taj način opisuju pojave iz svog obrazovnog iskustva. I Connelly i Clandinin (1990: 2) zaključuju da je naracija postupak koji se sve češće koristi $\mathrm{u}$ istraživanju iskustava učenika u obrazovnom procesu, što navodi na zaključak da je za vrstu istraživanja predstavljenu u ovom radu naracija najprikladniji način sakupljanja podataka da bi se ostvario zadati cilj istraživanja.

Podaci, bilo u kvantitativnom ili kvalitativnom istraživanju, skupovi su 
informacija (brojevi, reči, slike, video-zapisi, audio-zapisi, itd.) koje analiziraju istraživači (ili mašine) (Schreiber 2008). Analiza samih kvalitativnih podataka, u ovom slučaju naracije, odnosi se na analizu sadržaja, koju Julien (2008) definiše kao intelektualni proces kategorizacije kvalitativnih tekstualnih podataka u skupove sličnih entiteta, ili pojmovnih kategorija, u svrhu uočavanja doslednih obrazaca i odnosa između tema koje se javljaju. Ovde se, u stvari, radi o analitičkom metodu koji svodi veću količinu sakupljenih podataka na manji broj kategorija koje, potom, mogu da otkriju šire teme i pruže uvid u suštinu koja se krije iza podataka. Kad je reč o podacima koji se predstavljaju u ovom radu, postupak koji se primenjuje je kategorizacija studentskih zapažanja i uopštavanje dobijenih rezultata.

Materijal koji se analizira predstavlja izveštaje koje je pisao svaki student četvrte godine u školskoj 2011/12. godini, a odnosio se na odabir teme, pripremu, istraživanje, timski rad, izlaganje pred kolegama, reakcije kolega i nastavnika, kao i samokritički osvrt na celokupni projekat. Iz svih pomenutih grupa podataka deo svakog izveštaja koji se odnosi na istraživanje izdvojen je i analiziran po unapred utvrđenim parametrima, a podaci koji su dobijeni svrstani su u unapred utvrđene kategorije koje se odnose na stavove studenata prema istraživačkom procesu i istraživačke strategije koje su koristili prilikom istraživanja. Rezultati sa primerima iz samih studentskih izveštaja daju se u narednom odeljku.

\section{REZULTATI ISTRAŽIVANJA}

Detaljna analiza sadržaja 73 studentska izveštaja, koji se delom odnose i na proces istraživanja koji je prethodio izradi projekta za predmet Engleski jezik 9, otkriva tri velike kategorije podataka: stavove studenata, istraživačke strategije i preporuke za poboljšanje obrazovnog procesa u pogledu obučavanja studenata za istraživački rad.

\subsection{Stavovi studenata prema procesu istraživanja}

Kao što se i očekivalo na osnovu istraživanja iz Radić-Bojanić i Topalov (2012), više od pola studenata četvrte godine Engleskog jezika i književnosti, tj. $52,5 \%$, istraživački proces opisuje kao težak posao. Prethodno istraživanje je pokazalo da samokritičnost i svest o pomanjkanju istraživačkih veština raste sa 
godinama studija, što je verovatno posledica iskustva i sporadične edukacije koju studenti dobijaju tokom izrade seminarskih radova iz različitih predmeta na sve četiri godine studija. Tako studenti u analiziranim izveštajima svoje poteškoće opisuju na sledeći način:

- S4: Finding appropriate articles was not at all an easy task. (Pronalaženje odgovarajućih članaka nije uopšte bio lak zadatak.)

- S19: I was aware that I had a number of weaknesses in the sense that I lacked experience when it came to conducting research. (Bila sam svesna da imam nekoliko slabosti u smislu da mi nedostaje iskustvo kada se radi o obavljanju istraživanja.)

- S64: Since this was the first time I had to do research and collect sources for a project, the whole process of reading out the book, extracting the important facts, deciding what might be relevant, what might not, was extremely overwhelming and time consuming for me. (Pošto je ovo prvi put da sam morala da radim istraživanje i sakupljam izvore za projekat, ceo proces čitanja knjiga, vađenja bitnih činjenica, odlučivanja šta može biti relevantno a šta ne bio mi je veoma naporan i dugotrajan.)

- S10: I found conducting research very difficult due to the lack of experience in this field. (Istraživanje mi je bilo veoma teško zbog nedostatka iskustva u tom polju.)

- S37: What presented one of the major problems was the enormous amount of information, some of which was completely useless and served as distractors and a waste of time. (Ono što je bio jedan od najvećih problema je ogromna količina informacija od kojih su neke bile potpuno beskorisne i bile su distraktori i gubitak vremena.)

- S71: What I can say about my research is that it was hard for me to do and that I wasted a lot of time. (Ono što mogu da kažem o svom istraživanju jeste da mi je bilo teško i da sam izgubio dosta vremena.)

Dakle, može se zaključiti da su dva glavna izvora problema za studente u ovom slučaju bili neiskustvo u obavljanju istraživanja i nesposobnost da odrede stepen važnosti i relevatnosti izvora i informacija na koje su nailazili, što je, u krajnjoj liniji, posledica odsustva formalne obuke iz akademskog istraživanja. 
Druga grupa ustanovljenih stavova može se podvesti pod kategoriju averzije prema istraživanju, a ovakve stavove izražava 7,5\% studenata četvrte godine Engleskog jezika i književnosti. Ovi stavovi su, na neki način, ekstremne manifestacije prethodne grupe stavova, jer frustracije nekih studenata zbog neznanja o istraživačkom procesu dostižu vrhunac. Tako jedna studentkinja detaljno opisuje svoje iskustvo:

- S16: Although Hamlet is among the most famous literary works, I had only managed to find one different approach which includes this theory. This is probably due to my aversion towards internet research of this kind. When I come upon a long text or a book I cannot download but have to read on the internet, I stop putting much effort into it. (Iako je Hamlet među najpoznatijim književnim delima, uspela sam da pronađem samo jedan drugačiji pristup koji uključuje ovu teoriju. Razlog je verovatno moja averzija prema ovoj vrsti istraživanja na internetu. Kad naiđem na dugačak tekst ili knjigu koju ne mogu da skinem nego moram da čitam na internetu, prestanem da se trudim.)

$\mathrm{Na}$ osnovu njenog opisa, jasno je da koren frustracije leži u potpunom odsustvu istraživačkih strategija i strategija čitanja teksta, zbog čega ima utisak da je zadatak pretežak, te onda i odustaje u potpunosti.

Treća grupa ustanovljenih stavova je u potpunoj suprotnosti sa drugom, tj. studenti proces istraživanja opisuju kao lak i jednostavan. Doduše, u pitanju je samo 7,5\% studenata, i to onih koji tvrde da su tu veštinu razvili sami, kroz korišćenje interneta za druge svrhe. Tako jedan student kaže:

- S27: I have plenty of experience online, so I had no problems while conducting the research. I had retrived first-hand information from people dealing with dyslexia both in Serbia and abroad, via online forums, and collected all of the necessary information from websites of organizations dealing with this condition. (Imam mnogo iskustva onlajn pa nisam imao problema dok sam obavljao istraživanje. Došao sam do informacija iz prve ruke od ljudi koji se bave disleksijom i u Srbiji i u inostranstvu, putem onlajn-foruma, i sakupio sve potrebne informacije sa vebsajtova organizacija koje se bave ovim stanjem.) 
Iako ovaj student deluje veoma samouvereno i snalažljivo, i čini se kao da nije imao problema tokom procesa istraživanja za projekat, detaljnija analiza njegovog objašnjenja otkriva da pomenuta samouverenost proizlazi iz nekritičkog pristupa informacijama koje je našao na internetu (npr. informacije sa foruma, što nikako ne može da bude relevantan, naučni izvor). Stoga se treba zapitati da li je proces istraživanja tim studentima zaista bio jednostavan i lak, ili je prosto u pitanju odsustvo akademske kompetencije u proceni kredibiliteta izvora koje pronalaze na internetu.

Preostalih 32,5\% studenata nije u opisu projekta izražavalo mišljenje i stavove vezane za istraživački proces. Procentualna distribucija uzorka u ovom parametru analize može da se vidi na Dijagramu 1.

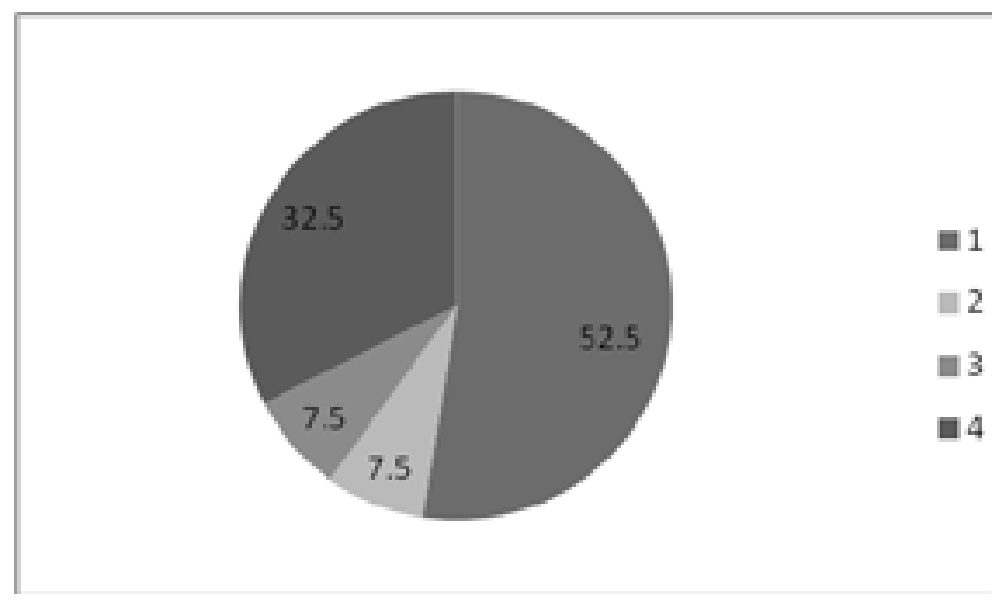

Dijagram 1. Procentualna distribucija stavova prema procesu istraživanja (1 - teško, 2 - averzija, 3 - lako, 4 - neopredeljeni)

\subsection{Istraživačke strategije studenata}

Analizom studentskih izveštaja utvrđeno je da su studenti četvrte godine Engleskog jezika i književnosti, prilikom pripreme projekta i traženja informacija, konsultovali tri izvora: internet, biblioteke i stručnjake iz oblasti. Kao što je i očekivano, najveći broj studenata, tj. 90\%, naveo je internet kao izvor informacija. Tačnije, studenti su navodili različite servise, baze podataka, sajtove, i sl., pa tako spominju Google, Google Scholar, Google Books, akademske baze Science Direct, 
Ebscohost, JSTOR, Elsevier, domaći repozitorijum KoBSON, ali i neakademske izvore kao što su razni sajtovi ili forumi. Istini za volju, uprkos velikom broju navoda o korišćenju interneta kao izvora informacija, jednako velik broj studenata taj izvor opisuje kao nepouzdan, a sebe kao nedovoljno kompetentne da bi ga sa sigurnošću koristili u akademske svrhe:

- S54: The problem when it comes to doing online research is evaluation and selection of sources. Articles posted without any critical assessment or review present a danger. Thus, it is always necessary to check the reliability of potential sources. (Problem sa onlajn-istraživanjem je evaluacija i selekcija izvora. Članci objavljeni bez ikakve kritičke procene ili recenzije predstavljaju opasnost. Stoga, neophodno je da se uvek proveri pouzdanost potencijalnih izvora.)

- S30: What I have discovered to be my greatest weakness as a researcher is that I do not know how to narrow down my search so as to find specific information. (Otkrio sam da je moja najveća slabost kao istraživača to što ne znam da suzim pretragu da bih pronašao specifične informacije.)

- S62: I had to read a large number of different articles and pieces of writing in order to carefully select the right source. (Morala sam da pročitam velik broj različitih članaka i tekstova da bih pažljivo odabrala pravi izvor.)

- S3: I knew I would have a problem with selecting relevant information and narrowing it down as much as possible. (Znala sam da ću imati problem sa odabirom relevantnih informacija i sužavanjem izbora koliko je to moguće.)

Drugi izvor informacija, knjiga i naučnih članaka koji su studenti koristili jesu biblioteke, tačnije biblioteka Filozofskog fakulteta u Novom Sadu i gradske biblioteke u Novom Sadu. Nažalost, samo 17,5\% studenata navodi da je tokom istraživanja za projekat otišlo u biblioteku i pozajmilo knjigu, iako je biblioteka Filozofskog fakulteta veoma dobro opskrbljena i u njoj se mogu naći nove, korisne i relevantne knjige. Šire posmatrano, studentski navodi svedoče o tome da su oni zaista pripadnici digitalne generacije koja koristi internet u velikoj meri i za velik broj različitih namena, ali i o tome da ih ova ponekad preterana usmerenost ka internetu sprečava da u akademskom životu iskoriste ono što im je lako dostupno i blizu. U stvari, ovaj podatak ukazuje na činjenicu da studenti skoro da nemaju 
naviku da koriste bibliotečke resurse, što svakako treba da se promeni sa budućim generacijama.

Naposletku, treći izvor informacija koji studenti navode su stručnjaci iz oblasti iz kojih su radili projekte. Tako $12,5 \%$ studenata navodi da su razgovarali sa nastavnicima iz osnovnih škola, sa prevodiocima, ili sa fakultetskim profesorima. Iako saveti koje studenti dobiju od stručnjaka mogu da budu veoma korisni, ne može se reći da su ovo validni akademski izvori informacija, jer stručnjaci samo mogu da studente upute na pisana i publikovana dela iz određene oblasti. Procentualna distribucija uzorka u ovom parametru analize može da se vidi na Dijagramu 2.

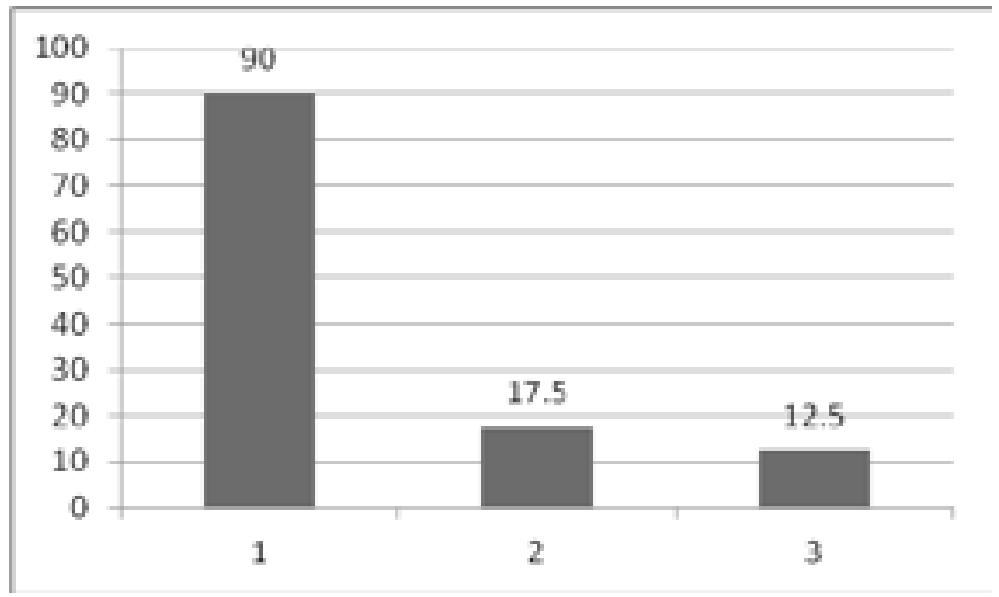

Dijagram 2. Procentualna distribucija stavova prema istraživačkoj strategiji (1 - internet, 2 - biblioteka, 3 - stručnjaci)

Još jedan zanimljiv podatak koji je otkriven prilikom analize studentskih izveštaja jeste činjenica da je nekoliko studenata, uvidevši da nemaju dovoljno znanja, veštine i kompetencije da samostalno istražuju za potrebe projekta, odlučilo da se obrazuje iz ove oblasti, te su pronašli knjige koje se bave istraživačkim procesom i obrazovanjem studenata iz te oblasti. To im je, po sopstvenom svedočenju, pomoglo da se lakše snađu i brže i kompetentnije pronađu potrebne informacije.

\subsection{Preporuke studenata}

Prilikom analize studentskih izveštaja uočena je još jedna kategorija podataka 
koja prvobitno nije predviđena. Naime, izvesni broj izveštaja $(27,5 \%)$ sadrži jasno izraženo mišljenje da bi na osnovne studije trebalo uvesti kurs koji će studente obučiti i naučiti kako da vrše akademsko istraživanje, kako da procenjuju validnost izvora i kako da se služe različitim resursima koji su im na raspolaganju:

- S29: I think more time should be devoted to teaching students how to properly use online search engines and make the most of the extremely valuable source of information that is the internet. (Mislim da bi trebalo posvetiti više vremena učenju studenata kako da pravilo koriste onlajn pretraživače i kako da najbolje iskoriste internet kao veoma vredan izvor informacija.)

- S46: I strongly believe that the program of our studies should contain several courses from the very first academic year that would encourage work on research skills, so students can become competent researchers, capable of finding what they are looking for and thus grow into independent and critically-thinking learners. (Zaista verujem da naš studijski program treba da sadrži nekoliko kurseva od prve godine studija koji bi podstakli razvoj istraživačkih veština tako da studenti mogu da postanu kompetentni istraživači, sposobni da nađu ono što traže i tako postanu nezavisni učenici sposobni za kritičko razmišljanje.)

- S40: A possible solution to this issue could include the introduction of an obligatory course, such as Academic writing, to all tracks (linguistic as well as literary), where students would learn (among other things) how and where to look for possible sources, as well as how to evaluate them. (Moguće rešenje ovog problema moglo bi da uključuje uvođenje obaveznog kursa kao što je Akademsko pisanje na sve module (jezički, kao i književni), gde bi studenti naučili (između ostalog) kako i gde da traže moguće izvore informacija, kao i kako da ih ocene.)

- S39: I feel that future generations would benefit from courses which would perhaps teach students how to do research on very specific, narrow fields, so that when given a project such as this, they can get straight into the research without wasting too much time as was the case with our group. (Mislim da bi buduće generacije imale koristi od kurseva koji bi možda naučili studente kako da vrše istraživanje u vrlo uskim oblastima, tako da kad dobiju projekat poput ovoga, mogu da odmah krenu da istražuju bez gubljenja previše 
vremena, kao što je bio slučaj sa našom grupom.)

Istini za volju, akreditovani plan i program osnovnih akademskih studija Engleskog jezika i književnosti sadrži predmet Akademsko pisanje, koji se bavi upravo razvojem ovakvih veština kod studenata, ali se nalazi na trećoj godini studija i predviđen je samo kao izborni predmet za studente književnog modula. Pošto književni modul bira neuporedivo manje studenata u odnosu na jezički, i pošto se u izbornoj poziciji nalazi i jedan metodički i jedan književni predmet, Akademsko pisanje bira vrlo mali broj studenata, a ponekad ga i niko ne bira. Jedino rešenje za ovu situaciju jeste, dakako, sistemskog tipa, tj. prebacivanje pomenutog predmeta na prvu godinu studija, gde bi predmet bio obavezan za sve studente. Ovo bi im omogućilo da od samog početka studija steknu znanja i veštine vezane za akademsko istraživanje i kritički stav prema informacijama koje nađu.

\section{ZAKLJUČAK}

Rezultati istraživanja mogu se sažeti na sledeći način: većina studenata četvrte godine Engleskog jezika i književnosti dovoljno je samokritična prema svojim istraživačkim veštinama i ima razvijenu svest o tome šta im predstavlja problem tokom istraživanja za dati projekat, dok manji broj studenata deluje samouvereno i obučeno za ovakav zadatak. Čini se da je ovaj potonji stav više posledica neznanja iz oblasti akademskog istraživanja, nego stvarne kompetencije. Sem toga, izvor informacija koji velika većina studenata koristi jeste internet, što se delom može objasniti činjenicom da studenti pripadaju digitalnoj generaciji, ali i time da su u pitanju studenti Engleskog jezika i književnosti , kojima je internet često prvi izbor zbog jezika koji studiraju i kojim se svakodnevno služe. Nažalost, mnogo ređe korišćen izvor informacija je biblioteka, iako se za biblioteku Filozofskog fakulteta može reći da je vrlo dobro opremljena i da sadrži najnovije knjige iz oblasti engleskog jezika i lingvistike, kao i anglofonih književnosti. Naposletku, nekolicina studenata uključenih $u$ istraživanje mišljenja je da na osnovne studije treba uvesti kurs iz Akademskog pisanja, što bi značilo da se sadašnji izborni kurs treće godine studija prebaci na prvu godinu i postane obavezan za sve studente.

Da bi se rezultati istraživanja kontekstualizovali i validnije objasnili, bilo 
bi potrebno uraditi komparativno istraživanje sa studentima sa drugih odseka, a možda i sa drugih fakulteta. Na taj način bi se dobila jasnija slika o istraživačkim veštinama i strategijama šire studentske populacije, ali bi se i utvrdilo koji su faktori presudni u tome što se studenti najčešće nekritički okreću internetu kao glavnom, a ponekad i jedinom izvoru informacija za akademsko istraživanje. U skladu sa dobijenim rezultatima, mogle bi se predložiti korektivne mere koje bi se integrisale $\mathrm{u}$ obrazovni proces na fakultetskom nivou, što bi dugoročno dalo dobre rezultate $\mathrm{i}$ poboljšalo kvalitet studentskih radova, a možda i umanjilo količinu plagiranih delova u studentskim radovima.

Sami studenti Engleskog jezika i književnosti u svojim izveštajima spominju jednu korektivnu meru koja bi sistemski mogla da reši problem istraživačke kompetencije studenata i kritičkog odnosa prema izvorima informacija, a to je uvođenje kursa iz Akademskog pisanja na samom početku studija. Na taj način studenti će se na vreme obučiti za akademski rad i naučiti strategije istraživanja i kritičkog čitanja teksta, što će svakako biti od velike pomoći kako studentima, tako i nastavnicima, koji će na ovaj način biti pošteđeni toga da uvek iznova, na svakom predmetu, objašnjavaju studentima kako da pristupe pisanju seminarskog rada ili istraživačkog projekta.

\section{LITERATURA}

Alexander, O. et al. (2008). EAP Essentials: A teacher's guide to principles and practice. Reading: Garnet Education.

Connell, F. M. i Clandinin, D. J. (1990). Stories of Experience and Narrative Inquiry. Educational Researcher 19/5: 2-14.

Eisner, E. W. (1991). The Enlightened Eye. Qualitative Inquiry and the Enhancement of Educational Practice. New York: Macmillan Publishing.

Julien, H. (2008). Content Analysis. The Sage Encyclopedia of Qualitative Research Methods. Thousand Oaks: SAGE Publications. [7. 12. 2008.] <http://www. sage-ereference.com/research/Article_n65.html>.

Manning, A. et al. (2007). Transferrable Academic Skills Kit. Reading: Garnet Education. 
Radić-Bojanić, B. i Topalov, J. (2012). Elektronski izvori COBISS i KoBSON u funkciji visokoškolskog obrazovanja: stavovi i navike studenata korisnika. Čitalište 20: 33-43.

Schreiber, J.B. (2008). Data. The Sage Encyclopedia of Qualitative Research Methods. Thousand Oaks: SAGE Publications. [7. 12. 2008.] <http://www.sageereference.com/research/Article_n93.html>.

Topalov, J. i Radić-Bojanić, B. (2012). Academic research skills with university students. Izlaganje na 22. međunarodnoj konferenciji British and American Studies u Temišvaru, 17-19.5.2012.

Tullis Owen, J.A. (2008). Naturalistic Inquiry. The Sage Encyclopedia of Qualitative Research Methods. Thousand Oaks: SAGE Publications. [7. 12. 2008.] $<$ http://www.sage-ereference.com/research/Article_n280.html $>$.

Biljana Radić-Bojanić

\section{RESEARCH SKILLS AND RESEARCH STRATEGIES OF ENGLISH LANGUAGE AND LITERATURE STUDENTS: QUALITATIVE ANALYSIS}

\section{Summary}

One of the first steps in academic writing, besides formulating a research question, is definitely finding references and relevant sources of information which will be used as a basis of new research. This is one of the most necessary skills, especially in the $21^{\text {st }}$ century, when the amount of information available online leads to saturation as well as a certain degree of impossibility to choose a good, relevant and reliable source. This paper tackles the issue of students' research skills and is based on the content analysis of 73 project reports of fourth year students of English Language and Literature. Relying on the qualitative approach to the narration in project reports, the paper will try to ascertain what problems students are faced with when researching for projects, what strategies they use while researching, and what solutions can be implemented in order to solve the problems established. The results of the research suggest that the majority of fourth-year students show a high level of awareness of the deficiencies they have regarding the research process, whereas a minority seems overly confident, which seems to be more a consequence of the lack of knowledge than of real training and skills. Furthermore, the major source for all students seems to be the internet, which can 
be explained partly by the fact that these students belong to the digital generation and using the internet is natural for them, while a much less frequently used source of information is the library. Finally, the solution for this situation, proposed both by the students and by the author of the paper, is the introduction of an obligatory Academic Writing course to the first year of studies so students can be trained in research skills and strategies, and so they can develop a critical attitude towards a variety of sources they find in the process of academic research.

Key words: academic writing, research skills, research strategies, solutions, qualitative analysis, narration. 